\title{
O ENCONTRO DE SABERES ACADÊMICO E ESCOLAR: EXPECTATIVAS DE INTERLOCUÇÃO E COMPARTILHAMENTOS DE SENTIDOS
}

\author{
THE MEETING OF ACADEMIC AND SCHOOL KNOWLEDGE: EXPECTATIONS \\ OF INTERLOCUTION AND SHARING OF MEANINGS
}

\author{
INTERLOCUÇÕES ENTRE SABERES ACADÊMICO E ESCOLAR
}

\section{INTERLOCUTIONS BETWEEN ACADEMIC AND SCHOOL KNOWLEDGES}

\author{
COHEN, Maria Cristina Ribeiro ${ }^{1}$ \\ "[...] o centro organizador de toda enunciação de toda expressão, não é interior, \\ mas exterior: está situado no meio social que envolve o indivíduo" (BAKHTIN \\ 1986, p. 121).
}

\begin{abstract}
Resumo
Este artigo apresenta as coordenadas filosóficas desenvolvidas por Bakhtin (1986 e 1979/2003) e os integrantes do seu círculo, relacionadas com o tema autor - autoria e os entendimentos destes múltiplos domínios de sentidos. Por considerar possível resgatar a noção de que a linguagem funciona diferentemente para diversos grupos na medida em que diferentes materiais configurados discursivamente participam do julgamento de uma dada situação, há um envolvimento em discussões que caracterizam o seu papel mediador e a natureza dos signos ideológicos produzidos em um determinado contexto de interação social o curso BIOgrafias e a abordagem discursiva da formação docente. Motivados pela necessidade de entender o funcionamento da linguagem social praticada no âmbito de eventos acadêmicos, procuramos compreender as enunciações docentes fazendo referência a contextos imediatos de sua produção, tais como: o processo de elaboração de textos relacionados com evento de pesquisa e o ensino - resultante da interface de práticas sócio históricas específicas.
\end{abstract}

Palavras-Chave: Teoria da Enunciação, Signos ideológicos, Autoria, Formação de professores.

\begin{abstract}
This article presents the philosophical coordinates developed by Bakhtin (1986 and 1979/2003) and the members of his circle, related to the author - authorship theme and the understandings of these multiple domains. Because it is possible to redeem the notion that
\end{abstract}

\footnotetext{
${ }^{1}$ Docente do curso de Licenciatura em Biologia. Universidade Federal do Triângulo Mineiro/UFTM. E-mail: criscohen@gmail.com
} 
language functions differently for different groups insofar as different discursively configured materials participate in the judgment of a given situation, there is an involvement in discussions that characterize its mediating role and the nature of the ideological signs produced in a particular context of social interaction - the BIOgrafias course and the discursive approach to teacher education. Motivated by the need to understand the functioning of the social language practiced in the context of academic events, we try to understand the teachers utterances referring to immediate contexts of their production, such as the process of preparation of texts related to the search event and education - resulting of the interface of specific socio-historical practices.

Keywords: Theory of Enunciation, Ideological Signs, Authorship, Teacher education

\section{INTRODUÇÃO}

A reflexão sobre o princípio autoral tem como finalidade o estabelecimento de um espaço diferenciado de discussão e compreensão sobre a multiplicidade de vozes presentes nos discursos docentes e a problematização das relações entre o lugar de onde se fala e a audiência para quem se dirige o autor desses discursos. Portanto, este artigo está organizado no seguinte desenho discursivo: após a explicitação de interesses e motivações, são apresentadas as coordenadas filosóficas desenvolvidas por Bakhtin (1986 e 1979/2003) e os integrantes do seu círculo ${ }^{2}$, relacionadas com o tema autor - autoria e os entendimentos destes múltiplos domínios de sentidos, na esfera dos estudos da linguagem. Por considerar possível resgatar a noção de que a linguagem funciona diferentemente para diversos grupos na medida em que diferentes materiais configurados discursivamente participam do julgamento de uma dada situação, há um envolvimento em discussões que caracterizam o seu papel mediador e a natureza dos signos ideológicos produzidos no processo de interação social ${ }^{3}$.

\section{Professores como autoridade nos campos de conhecimento e atuação}

Com a intenção de entender, através de discursos diversos, "vozes sociais, objetos, sentidos, valores, formas de representação e expressão e valores constituintes de seus dizeres"

\footnotetext{
${ }^{2}$ A edição biográfica, de Katerina Clark e Michael Holquist, lançada em 1984, revela que ao longo dos anos 20, Bakhtin participou de um grupo de discussões culturais, filosóficas e religiosas de que faziam parte, entre outros, Voloshinov e Medvedev, grupo definido mais tarde como o 'Círculo de Bakhtin' (TEZZA 2003, p. 25).

${ }^{3}$ Situações cotidianas ao envolverem contextos de interação sócio-verbal caracterizam-se por: (I) presença de interlocutores, (II) coloquialidade e (III) alto grau de conhecimentos partilhados e cooperação mútua. A estas, são acrescentadas outras considerações relativas a acontecimentos específicos que envolvem o registro escrito: (I) as necessidades sociais que implicam no aprimoramento dos usos sociais da escrita e que (II) na produção escrita, a interação sócio-verbal dar-se a distância.
} 
(COHEN, 2004 e COHEN; MARTINS, 2008) e por comprometimento com experiências possibilitadoras de novos saberes, buscamos iniciativas que revelem e realcem interfaces entre os universos discursivos acadêmicos e escolares, de pesquisadores e de professores; porém, atentas em não dicotomizar aspectos ou pontos de vista instituidores ou de reforço de (de)semelhanças entre eles. Nesse sentido, o espaço escolar é caracterizado e (re)conhecido como um espaço complexo, histórico, múltiplo; isto é, como “ (...) local de encontro e contenda entre sentidos e sujeitos historicamente constituídos e singulares que se constituem em condições que articulam linguagem, pensamento e prática social” (COHEN 2004, p. 47).

Estas implicações estão voltadas para as competências e reflexão dos saberes docentes e as entendem como socialmente construídos e partilhados por conta de processos de imersão em mundos socializados diversos - familiar, escolar, acadêmico, entre outros. Contudo, esses saberes plurais muitas vezes nem são registrados ou discutidos de forma sistemática visando a sua difusão por uma outra via que extrapole as trocas orais nos ambientes escolares ${ }^{4}$. De acordo com Tardif (1999), “(...) para os professores, por exemplo, nem sempre é fácil teorizar a sua prática e formalizar seus saberes, que eles veem como sendo pessoais, tácitos e íntimos” (TARDIF,1999, p. 32).

\section{Quais as expectativas dos docentes da escola básica na interação sócio verbal mediada pela escrita?}

Estudos anteriores (COHEN, 2010 e COHEN, 2013) apontam que os encontros promovidos por sociedades científicas e/ou profissionais, ao reunir diferentes perfis profissionais, configuram-se como espaço de troca, revelador de diálogo entre esferas sociais distintas - acadêmica e escolar ${ }^{5}$. As instituições acadêmicas, muitas vezes, realizam diversos encontros visando compreender e constituir o seu público e construindo, desta forma a visão de audiência dos eventos por elas promovidos, posto que a posição de seus interlocutores e destinatários influencia na construção enunciativa. Assim sendo, as atividades desenvolvidas nesta esfera são geradoras de gêneros discursivos específicos, os quais, do ponto de vista temático e estilístico-composicional são relativamente estáveis e mais padronizados (BAKHTIN,1979/2003), configurados em função de um conjunto de parâmetros que exercem

\footnotetext{
${ }^{4}$ Quando os professores elaboram seus planos de curso e as estratégias de ensino nos seus planejamentos das aulas com o propósito de entrelaçar os conteúdos programáticos, produzem gêneros discursivos pertencentes a sua específica esfera social de trabalho.

${ }^{5}$ Os encontros acadêmicos caracterizam-se como uma forma de relação social relativamente estável (a relação entre o dado e o novo) que se estabelece através do uso da linguagem.
} 
influência sobre a maneira como são organizados. O encontro de posições sócio axiológicas é situado e entendido como um espaço social de ações e locus de (res)significação de sentidos, de (re)conhecimento de identidades profissionais e de práticas sócio-histórico-culturais, para além de uma visão deste como “ (...) arena social, dialógica, de locus de referências para os professores da escola básica e locus institucional que outorga, através do seu comitê científico, autoridade aos discursos desses professores, ao conferi-los credibilidade" (COHEN 2010, p 15-16).

A partir dessas concepções e por entender que o conhecimento teórico é fundamental para o professor assumir-se como autor de seu discurso, algumas incursões sobre práticas autorais - as relações entre o lugar de onde se fala e a audiência para quem se dirige o autor dos discursos serão apresentadas a seguir.

\section{O que caracteriza apreender os significados do contexto sócio histórico e compreender o exercício de negociação das múltiplas linguagens?}

A palavra escrita, no sentido bakhtiniano do termo, é o "espaço de centralização da linguagem" (TEZZA 2006, p. 245). Se o signo ideológico bakhtiniano se configura enquanto uma arena de luta pela significação, vale ressaltar que a esfera discursiva evento acadêmico passa a se configurar, portanto, como espaço discursivo; ou seja, como uma arena de luta não apenas pela significação, mas também por considerar a cultura letrada. Em função do atendimento às necessidades da esfera acadêmica, a produção docente representa um esforço de alinhamento às regras, revelador de escolhas docentes. Contudo, há necessidade de se destacar que há um envolvimento do autor com seus interlocutores e destinatários presumidos através de múltiplas abordagens e sentidos construídos. Ao fazê-lo, o mesmo coloca-se na origem do seu dizer - o que foi experienciado em sua trajetória docente por meio de um processo de reflexão sobre sua prática e de (re)construção de identidade pessoal e profissional que, de certa forma, autoriza a inserção de seu discurso em um específico contexto sócio histórico.

Com base nos pressupostos teóricos que enfatizam o caráter social e histórico das produções discursivas (BAKHTIN, 1986 e BAKHTIN,1979/2003), a linguagem é 
compreendida na sua dimensão constitutiva ${ }^{6}$, problematizadora de questões relacionadas com os contextos nos quais as enunciações ocorrem.

\section{Articulando significados sobre o processo de autoria}

Para Bakhtin (1979/2003, p. 11), autor é aquele participante do todo da obra e que nela vê e conhece para além daquilo que cada personagem em particular e todas as personagens juntas enxergam e conhecem. A partir de específicos contextos sócio históricos, sentidos são construídos entre autor e leitor. Assim sendo, as posições entre autor e leitor (co-autor do texto) e o sentido atribuído àquilo que se lê são definidos por processos sócio históricos e por condições de produção, circulação e consumo. Deste modo, o autor é um organizador daquilo que acontece no mundo e o que o caracteriza como autor é a maneira singular como organiza, segundo sua ideologia, a(s) linguagem(ns) e os acontecimentos. Por exemplo, no caso da esfera sócio-discursiva, evento acadêmico que exige um emprego de registro escrito mais formal, esse duplo aspecto da autoria é especificamente relevante porque permite a explicitação de como o professor reflete e/ou refrata a posição discursiva referente a esta esfera - evento acadêmico e, assim, posicionar-se como autor-pessoa ou como autorcriador. "Viver é continuamente tomar posição; é se posicionar em quadros de valores; é responder axiologicamente" (BAKHTIN 1979/2003, p. 3).

\section{Procedimentos de análise investigativa acerca dos propósitos discursivos docentes - algumas contribuições}

Quando propomos uma análise discursiva acerca dos sentidos que dê conta do discursivo e do não discursivo, fazemos referência a uma opção investigativa que se ocupe do visível e do enunciável de determinados discursos vinculados às específicas esferas acadêmica e escolar. Interessa-nos, em particular, considerar o espaço ou esfera discursiva que se abre para uma relação de autoria, configurado tanto pela assunção de um propósito discursivo quanto por um exercício reflexivo que o professor realiza nos espaços que lhe são possibilitados.

Nesse contexto, apresentamos um recorte resultante da experiência surgida de um convite da Diretoria Regional RJ/ES da SBEnBio (Associação Brasileira de Ensino de

\footnotetext{
${ }^{6}$ Abordagens constitutivas da linguagem estão centradas no questionamento de "quem diz o quê? para quem? onde? quando? e para quê?"”
} 
Biologia) para ministrar o curso de extensão "BIOgrafias": oficina de produção de textos com professores".

Portanto, com base na teoria da enunciação, os princípios organizadores de uma análise investigativa preliminar buscam explorar: (I) as relações entre os enunciados presentes nos textos e as demandas da situação discursiva que circunscrevem a produção textual; isto é, o entendimento acerca da proposta de inscrição na esfera discursiva evento acadêmico e (II) os aspectos das práticas sociais nas quais tomam parte os professores, tais como as condições sociais das construções discursivas, as interlocuções presentes nos ambientes profissionais e acadêmicos etc.

Com base no entendimento de que alguns gêneros discursivos mostram-se mais adequados para a inscrição do professor na posição de autor, para iniciar a discussão, foi solicitada a formulação de duas perguntas ou questões sobre produção de textos que gostaria que fossem respondidas ao longo da atividade. Destacamos no quadro a seguir:

Quadro 01:

\begin{tabular}{|c|}
\hline $\begin{array}{l}\text { Como iniciar a produção de um texto? (sem contar com as } \\
\text { leituras de referências) }\end{array}$ \\
\hline Como começar? \\
\hline $\begin{array}{l}\text { Como começar? Como iniciar a produção de um texto? } \\
\text { (sem contar com as leituras de referências) }\end{array}$ \\
\hline $\begin{array}{l}\text { Os textos podem ser em forma de relato ou devem seguir } \\
\text { um padrão específico? }\end{array}$ \\
\hline $\begin{array}{l}\text { Diferenças entre texto de produção científica e texto de } \\
\text { produção não científica? }\end{array}$ \\
\hline $\begin{array}{l}\text { O conteúdo deve ser sempre sobre E-A } \\
\text { [Ensino } \\
\text { Aprendizagem] ou pode ser focador em } \\
\text { vivências/contextos/relacionados ao contexto? }\end{array}$ \\
\hline $\begin{array}{l}\text { Quais os padrões métricos fundamentais para textos de } \\
\text { produção acadêmica? }\end{array}$ \\
\hline $\begin{array}{l}\text { Até que ponto devemos estudar bibliografia e perguntar } \\
\text { sobre o tema e partir para a escrita? }\end{array}$ \\
\hline es e suas obras? \\
\hline es dialogam? \\
\hline Como quem escreve dialoga como os autores? \\
\hline $\begin{array}{l}\text { Que aspectos devem ser considerados no momento da } \\
\text { revisão de texto? }\end{array}$ \\
\hline $\begin{array}{l}\text { Como se livrar da redundância juntamente com a repetição } \\
\text { desnecessária de palavras e ideias ao escrever um texto? }\end{array}$ \\
\hline
\end{tabular}

\footnotetext{
${ }^{7}$ Realizado na última semana de março de 2017, na Faculdade de Formação de Professores da UERJ - São Gonçalo, RJ, o curso foi promovido em parceria com o Programa de Pós-graduação em Ensino de Ciências, Ambiente e Sociedade da FFP UERJ e com o Grupo de Egressos do Curso de Ciências Biológicas da FFP UERJ. Está integrado à organização do VIII Encontro Regional de Ensino de Ciências - VIII EREBIO RJ/ES, que ocorrerá em meados de setembro deste ano.
} 
Quais são os principais critérios utilizados pelos avaliadores, além da formatação textual e o assunto que

deve ser alinhado aos temas da revista?

Quadro - formulações dos cursistas sobre a produção textual

Na teoria do gênero do filósofo russo Mikhail Bakhtin (1979/2003), todo gênero: envolve um tema - o tipo de fato para o qual ele se volta; assume uma forma composicional a organização geral do texto, como introdução, desenvolvimento e conclusão; define um estilo - o tom característico desse discurso, mais ou menos pessoal, mais ou menos formal etc. Todos esses enfoques estão formulados nas questões docentes: necessidade de caracterização de gêneros discursivos relativamente estáveis, tema, estrutura, estilo e os supra destinatários - corpo de árbitros (pareceristas) além das abordagens dialógicas, de discursos unívocos, de autoridade, das diversas produções de sentidos etc . Aprender a escrever envolve aprender a construir imagens adequadas de interlocutores e destinatários quanto compreender as condições em que se presume a realização da leitura; isto é, o suporte de veiculação, a situação imediata e o contexto sócio histórico ideológico para, a partir destas construções, o professor orientar-se nos modos de organização, explicitação e articulação de seus conhecimentos.

Portanto, pensar o processo autoral a partir do contexto sócio histórico em que se insere o autor, significa pensar o processo de aquisição da escrita como uma de suas etapas, pois é através da articulação deste processo que o sujeito desloca-se da posição de enunciador para se transformar em autor.

\section{Articulação entre aquisição da escrita e processo autoral - conjunção das necessidades sociais dos professores}

Pensar sobre as práticas sociais de leitura e escrita como atividades de linguagem implica em integrar histórias de professores que evidenciem em suas produções discursivas, o reflexo e/ou a refração das condições sociais, culturais, educacionais e econômicas em uma dada época e certa situação. Consequentemente, os docentes necessitam apreender os significados do contexto evento acadêmico e compreender o exercício de negociação das múltiplas linguagens e seus efeitos na constituição de sujeitos comprometidos com os resultados de pesquisa no campo da educação presentes no cotidiano escolar. Significa que no processo de formação identitária deve fazer diferença na maneira como cada sujeito vai perceber e tratar as práticas sociais que lhe são demandadas em seus contextos sócio verbais. 
Em outras palavras, uma vez que as práticas sociais de uso das linguagens pressupõem o uso de diferentes gêneros discursivos, ter competência para utilizar a escrita em práticas discursivas específicas, como em eventos acadêmicos, implica referir-se diretamente a uma sociedade grafocêntrica, na qual o sujeito está inserido em um círculo letrado e que de acordo com suas necessidades, faz distintos usos de competência leitora e de produção de artigos acadêmicos ${ }^{8}$; porém, relacionadas à apreciação valorativa da situação enunciativo-discursiva. Considera-se que a interação sócio-verbal mediada pela escrita ${ }^{9}$ difere do que ocorre na maioria das interlocuções cotidianas ${ }^{10}$. Ainda que ao enunciarem, os professores imaginem ser a fonte daquilo que é dito e acreditem compreendido como pretendiam; ou seja, como se o sentido fosse transparente, esses discursos estão imbricados, entrelaçados e os constituindo em suas formações formativas e profissionais.

No entendimento de linguagem enquanto prática social de significação que estrutura experiências cotidianas, reconstrói relações interpessoais e se manifesta na forma de produções sócio-situadas, o que importa são os usos sociais dos discursos docentes; isto é, como os professores significam socialmente as restrições impostas pela esfera sócio ideológica em que o gênero se expressa - artigo acadêmico, afetando a liberdade de seus projetos discursivos. Por certo, a posição como professor da escola básica, bem como os antecedentes acadêmicos possibilitados durante a formação inicial e continuada, influenciam a maneira de conceber e de se apropriar do conceito do gênero discursivo artigo acadêmico. De acordo com Bakhtin (1986, p. 95), “... É por isso que os membros de uma comunidade linguística, normalmente não percebem nunca o caráter coercitivo das normas linguísticas”.

A produção de um artigo que será submetido à avaliação externa e, se aprovado, posteriormente publicado em Anais de Eventos acadêmicos consiste numa aproximação à esfera acadêmica, que valoriza não só a produção escrita como também a organização

\footnotetext{
${ }^{8}$ Artigo acadêmico compreendido como uma produção discursiva em que o autor desenvolve e apresenta, para apreciação, um conhecimento ou conteúdo que pode ser amplo e/ou variado, no qual descreve, explica, argumenta, interpreta ou avalia uma situação episódica ou uma concepção de especial interesse, segundo sua conformidade.

${ }^{9}$ Em que a interlocução não é mais imediata e que as condições de produção discursiva se tornam mais complexas, com locutores/ autores e interlocutores distantes, na qual estes últimos não podem solicitar esclarecimentos e nem os autores podem acrescentar nada além do que já escreveram.

${ }^{10}$ Ao ouvir e responder perguntas ou até mesmo em algumas situações mais formalizadas em que é possível orientar-se pelas reações dos interlocutores na (re)condução dos movimentos discursivos, como um debate, uma conferência, entre outras.
} 
discursiva, como forma de produção social de sentidos ${ }^{11}$. O contato constante com o gênero de produção discursiva que essa escrita organiza (e é organizado) torna-se constituinte das condições da consciência linguística dos professores $^{12}$.

\section{A audiência constituindo a produção do autor/ escritor - o trabalho colaborativo}

No princípio bakhtiniano, autor é entendido como aquele que, ao mesmo tempo, reflete e refrata; é aquele que conhece algo que é inacessível às personagens, exatamente porque a ele é atribuído um excedente de visão, pelo seu estar de fora (BAKHTIN 1979/2003, p. 21-23). A criação de um espaço de autoria de textos reflete a demanda por espaços de atualização e reflexão sobre as questões pertinentes ao campo educacional e, por outro, estimula e legitima as contribuições docentes elaboradas por sujeitos que enunciam de posições discursivas e horizontes sócio conceituais distintos daqueles de onde enunciam pesquisadores e professores universitários.

\section{CONSIDERAÇÕES GERAIS}

Para Bakhtin (1986, p. 146-147), tanto as formas de apreensão quanto de verbalização do discurso de outrem são construídas em meio a tendências sociais estáveis, segundo formas padronizadas para sua introdução, o que implica, deste modo, que a avaliação de sua adequação e sua valoração estética são fundamentalmente sociais. As concepções e noções privilegiadas neste estudo buscam refletir acerca do processo de autoria e de que o autor se constitui a partir de um investimento empreendido discursivamente pelo sujeito. Este empreendimento dá ao professor condições de escolher e veicular pontos de vista diversos e, com isto, encontrar contrapontos necessários para apresentar e compartilhar significados sociais com seus interlocutores.

Uma vez compartilhada a concepção de que a língua é um sistema de signos construídos histórica e socialmente, que possibilita aos sujeitos significar o mundo que os cercam e no qual estão inseridos, conhecer a língua significa saber se movimentar dentro dela. Entretanto, há necessidade de reiterar que formar não é apenas dar forma $a$, mas envolve

\footnotetext{
${ }^{11}$ Busca-se compreender as especificidades dessas distintas esferas ideológicas e como estas se refletem ou refratam nos discursos docentes; ou seja, o quanto o movimento dialógico se aproxima ou se distancia nos discursos dos professores ao fazer referências a contextos imediatos de produção.

${ }^{12}$ Aprender a linguagem seja ela a utilizada no cotidiano, no espaço escolar ou as vinculadas a eventos acadêmicos e veiculadas em artigos acadêmicos, não é apenas aprender as palavras e saber codificá-las e decodificá-las.
} 
estratégias que dão lugar a outros modos de relação com os mundos acadêmico e escolar, com outros sujeitos - pares e pesquisadores -, com aprender e com conhecer.

\section{Referências}

BAKHTIN. M. M. Marxismo e Filosofia da Linguagem. $3^{\text {a }}$ Ed. São Paulo: Editora Hucitec, 1986.

BAKHTIN, M. M. Estética da criação verbal. trad. Paulo Bezerra. São Paulo: Martins Fontes, 1979/2003.

COHEN, M. C. R. Movimentos enunciativos em projetos de educação em / para saúde: lugar das determinações sociais nos discursos dos professores. Núcleo de Tecnologia Educacional para a Saúde. Universidade Federal do Rio de Janeiro. NUTES/UFRJ (Dissertação de Mestrado), 2004.

COHEN, M. C. R.; MARTINS, I. Discursos de profesores de los ciclos iniciales de enseñanza primaria acerca de las relaciones entre escuela, salud y medio ambiente. Enseñanza de las Ciencias. Revista de investigación y experiencias didácticas. v. 26, n.1, p. 53 - 65, 2008.

COHEN, M. C. R. As interfaces e fronteiras no autorar: textos de professores apresentados em eventos de ensino de biologia. Núcleo de Tecnologia Educacional para a Saúde. Universidade Federal do Rio de Janeiro. Rio de Janeiro-RJ. Tese (Doutorado em Educação em Ciências e Saúde), 2010.

COHEN, M.C.R. Autoria e compartilhamentos de saberes: contribuições para a formação de professores de ciências/ biologia. Anais. IX Encontro Nacional de Pesquisa em Educação em Ciências/ IX ENPEC. Águas de Lindóia: SP, 2013.

TARDIF, M. Saberes profissionais dos professores e conhecimentos universitários. Rio de Janeiro: PUC, 1999.

TEZZA, C. Entre a prosa e a poesia: Bakhtin e o formalismo russo. Rio de Janeiro: Rocco, 2003.

TEZZA, C. Sobre a autoridade poética. In: FARACO, C. A; TEZZA, C.; CASTRO, G. (orgs.) Vinte Ensaios sobre Mikhail Bakhtin. Petrópolis. RJ: Editora Vozes, 2006, p. 235 - 254. 